\title{
Three-dimensional cathodoluminescence imaging and electron backscatter diffraction: tools for studying the genetic nature of diamond inclusions
}

\author{
D. F. Wiggers de Vries $\cdot$ M. R. Drury • \\ D. A. M. de Winter · G. P. Bulanova • \\ D. G. Pearson · G. R. Davies
}

Received: 17 December 2009/ Accepted: 26 June 2010/Published online: 13 July 2010

(C) The Author(s) 2010. This article is published with open access at Springerlink.com

\begin{abstract}
As a step towards resolving the genesis of inclusions in diamonds, a new technique is presented. This technique combines cathodoluminescence (CL) and electron backscatter diffraction (EBSD) using a focused ion beamscanning electron microscope (FIB-SEM) instrument with the aim of determining, in detail, the three-dimensional diamond zonation adjacent to a diamond inclusion. EBSD reveals that mineral inclusions in a single diamond have similar crystallographic orientations to the host, within $\pm 0.4^{\circ}$. The chromite inclusions record a systematic change in $\mathrm{Mg} \#$ and $\mathrm{Cr} \#$ from core to the rim of the diamond that corresponds with a $\sim 80^{\circ} \mathrm{C}$ decrease of their formation
\end{abstract}

Communicated by J. L. R. Touret.

Electronic supplementary material The online version of this article (doi:10.1007/s00410-010-0550-y) contains supplementary material, which is available to authorized users.

D. F. Wiggers de Vries $(\bowtie) \cdot$ G. R. Davies

Faculty of Earth and Life Sciences,

VU University Amsterdam, De Boelelaan 1085,

1081 HV Amsterdam, The Netherlands

e-mail: daphne.wiggers.de.vries@falw.vu.nl

\section{R. Drury}

Department of Earth Sciences, Utrecht University,

Postbus 80021, 3508 TA Utrecht, The Netherlands

D. A. M. de Winter

Biomolecular Imaging, Faculty of Sciences,

Utrecht University, $3584 \mathrm{CH}$ Utrecht, The Netherlands

G. P. Bulanova

Department of Earth Sciences, University of Bristol, Wills

Memorial Building, Queen's Road, Bristol BS8 1RJ, UK

D. G. Pearson

Department of Earth Sciences, Durham University,

Science Labs, Durham DH1 3LE, UK temperature as established by zinc thermometry. A chromite inclusion, positioned adjacent to a boundary between two major diamond growth zones, is multi-faceted with preferred octahedral and cubic faces. The chromite is surrounded by a volume of non-luminescent diamond (CL halo) that partially obscures any diamond growth structures. The CL halo has apparent crystallographic morphology with symmetrically oriented pointed features. The CL halo is enriched in $\sim 200 \mathrm{ppm} \mathrm{Cr}$ and $\sim 80 \mathrm{ppm} \mathrm{Fe}$ and is interpreted to have a secondary origin as it overprints a major primary diamond growth structure. The diamond zonation adjacent to the chromite is complex and records both syngenetic and protogenetic features based on current inclusion entrapment models. In this specific case, a syngenetic origin is favoured with the complex form of the inclusion and growth layers indicating changes of growth rates at the diamond-chromite interface. Combined EBSD and 3D-CL imaging appears an extremely useful tool in resolving the ongoing discussion about the timing of inclusion growth and the significance of diamond inclusion studies.

Keywords Diamond inclusions - Diamond zonation . Three-dimensional cathodoluminescence (3D-CL) . Inclusion genesis - Focused ion beam (FIB) . Electron backscatter diffraction (EBSD)

\section{Introduction}

Inclusions in diamonds are considered vital for understanding diamond petrogenesis because they retain a record of $\mathrm{P}-\mathrm{T}$ conditions, information on the mineralogical and geochemical environment of diamond formation and timing of diamond growth. Most studies of diamond inclusions assume simultaneous formation of diamond and inclusion, 
although this syngenetic origin remains unverified in many cases.

Mineral inclusions in diamonds are divided into three groups according to their timing of growth relative to the diamond host: (1) protogenetic, i.e., crystallisation of a mineral before being trapped by diamond, (2) syngenetic, i.e., co-crystallisation of inclusion and diamond and (3) epigenetic, i.e., formation or modification of inclusion after diamond formation. Cracks that developed after growth can connect an inclusion to the diamond surface, and any alteration process could modify the inclusion and transform it into an epigenetic inclusion. The absence of cracks or healed cracks can readily be verified with CL imaging of the diamonds and establishes whether diamond inclusions are epigenetic.

Inclusions often have epitaxial intergrowth with diamond and imposed octahedral diamond morphology (Bulanova 1995; Futergendler and Frank-Kamenetsky 1961; Harris and Gurney 1979; Leeder et al. 1987; Meyer 1985, 1987; Mitchell and Giardini 1953; Orlov 1977; Pearson and Shirey 1999; Sobolev 1977), and these criteria support a syngenetic origin. Mineral inclusions located across different zones of single diamond crystals sometimes record a gradual chemical change in composition that is explained by their successive formation during growth of the diamond host (Bulanova 1995). In addition, the relationship between eclogitic (E-type) and peridotitic (P-type) inclusion paragenesis and the range in carbon isotope composition of the host diamonds indicates that there is a genetic relation between the type of mineral inclusion and the diamond host (Pearson and Shirey 1999; Sobolev et al. 1979). Therefore, it is generally assumed that the inclusions formed simultaneously with the diamonds and are accordingly syngenetic.

In contrast, Taylor et al. (2003b) argued that rare earth elements (REE) from harzburgitic garnet inclusions are inconsistent with simultaneous growth with diamond and proposed a protogenetic origin for these inclusions. The REE patterns are sinusoidal-shaped and suggest a multistage history for these garnets: partial melting, metasomatic enrichment and potentially another final phase of partial melting. The complex petrogenetic history of these inclusions led these authors to suggest formation and modification of the garnets before they are trapped by the diamond. In addition, Spetsius et al. (2002) report sulphide inclusions in zircon megacrysts from the Mir kimberlite (Yakutia) that have significantly older model ages than their hosts. These authors inferred a metasomatic origin for the zircons whereby the trapped inclusions underwent little elemental or isotopic modification; however, no isochron relationship was shown by the sulphides. Together these studies suggest that some inclusions and their host may not necessarily be syngenetic. Other studies have found minerals belonging to both the eclogitic and peridotitic paragenesis in a single diamond, indicating the complexity of petrogenetic information that can be contained within a single diamond (Wang 1998). Hence, further study of the detailed relations between inclusion and host diamond is required to better understand their genetic relations.

Another criterion to resolve the genetic origin of inclusions is the geometry of diamond zonation directly around an inclusion. In theory, the geometry of host zones around proto- or syngenetic inclusions should be completely different (Bulanova 1995). Diamond growth layers can grow around an inclusion, while the inclusion has its own morphology, i.e., no imposed morphology (protogenetic), or alternatively, diamond growth layers can crosscut an inclusion that has an imposed cubic diamond morphology with many imposed faces (syngenetic).

The aim of this paper is to evaluate the potential of studying inclusion-diamond relationships with a combined three-dimensional cathodoluminescence (3D-CL)-electron backscatter diffraction (EBSD) technique performed using a focused ion beam-scanning electron microscope (FIBSEM) (De Winter et al. 2009; Wirth 2009). The technique is used to determine in detail diamond growth layers adjacent to a diamond inclusion and crystallographic orientations of the diamond and its inclusions. This contribution is designed to assess the resolution of the technique and the viability of its use in unambiguously assessing if inclusions in diamonds are syn- or protogenetic.

\section{Sample}

The octahedral macro-diamond \#3615 from the Udachnaya kimberlite pipe in Yakutia (Russia) was selected for combined FIB-SEM study because of the distinct growth patterns and presence of inclusions (Fig. 1). A $<2$-mm-thick plate was prepared by polishing. The plate is a section through the centre of the octahedral diamond, and both planes are polished parallel to $\{110\}$ surfaces. A detailed mineralogical and geochemical examination of the diamond and its inclusions has been performed to fully characterise its growth history. It has been subjected to CL imaging, detailed microscopy and characterised for nitrogen content and nitrogen aggregation state by infrared spectroscopy. Fourier transform infrared (FTIR) spectra were taken at the Diamond High Council (HRD) in Lier, Belgium. The nitrogen content and nitrogen aggregation state are determined following the methods of Mendelssohn and Milledge (1995) and Taylor et al. (1990). Elemental data on mineral inclusions have been presented by Bulanova (1995) and Bulanova et al. (1998), and elemental impurity contents of the diamond are determined by electron microprobe (EMP).

Diamond \#3615 was selected from a collection of 150 well-characterised inclusion-bearing Yakutian diamonds. 

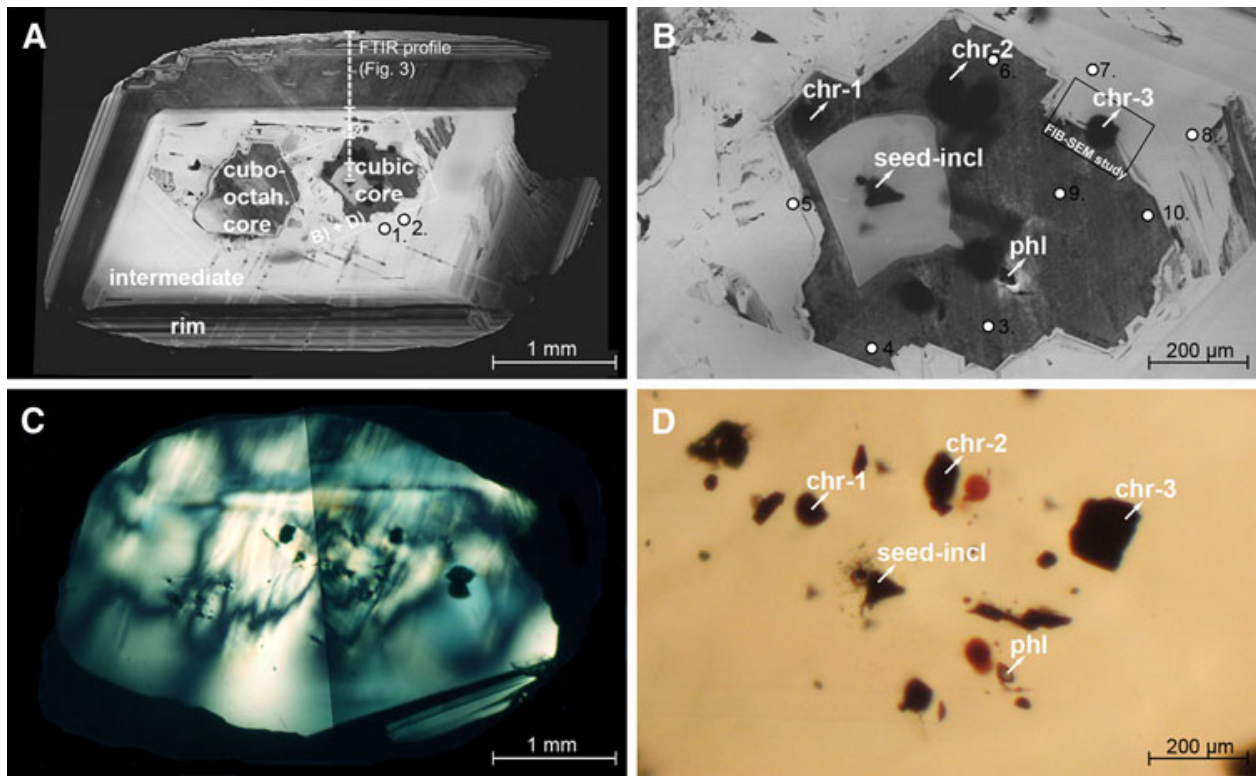

Fig. 1 a CL image of the central section of diamond \#3615, Yakutia. This elongated, octahedral crystal has two cores: a cubo-octahedral (left) and a cubic (right). Linear tracks induced by proton microprobe occur across the plate. b CL image of the cubic core. The five inclusions that are exposed on the surface are indicated (chr $=$ chromite; $\mathrm{phl}=$ phlogopite, seed-incl $=$ seed inclusions in the centre of core). Rounded ion microprobe pits and traverses with distinct CL occur in the core area. The chromite inclusion selected for combined FIB-SEM study (chr-3) is located near the core-intermediate contact

In the majority of cases ( $>90 \%)$, inclusions in this collection occur in diamond growth zones without obvious micron-scale zonation. Moreover, Taylor et al. (2003a) noted that diamond inclusions are often surrounded by micron-scale zones without zonation, i.e., "CL deadzones". Nonetheless, the chromite inclusion that was chosen for 3D-CL is located near the boundary between the diamond's outer cubic core and the octahedral intermediate area, i.e., near a very distinct CL contact (see chromite-3 in Fig. 1b). The objective of the 3D-CL study is to examine the geometry of this core-intermediate contact adjacent to the chromite inclusion to reveal the genetic relationship between the inclusion and diamond host.

\section{Methods: Technique on combined FIB-SEM instrument}

\section{Electron backscatter diffraction}

While previous studies of diamond inclusions mainly used X-ray diffraction techniques to determine the inclusions' orientations (e.g., Mitchell and Giardini (1953); Futergendler and Frank-Kamenetsky (1961)), the advantage of EBSD is that it quantitatively identifies crystal directions at (see blow-up Fig. 5). c Birefringence image. The patterns correlate with the zones that are observed with CL imaging. It also shows the presence of many inclusions (that are mainly concealed at depth). Most inclusions are present in one of the two cores. d Transmitted light image of the cubic core. It shows the presence of many inclusions concealed at depth. The five exposed inclusions are indicated. This image appears out of focus because of the different depth levels of each inclusion. The numbers indicate EMP analysis of major element concentrations in the diamond (see Table 2)

individual points (Fliervoet et al. 1999; Prior et al. 1999). In an EBSD study, Cayzer et al. (2008) reported lattice mismatches in lower mantle diamonds of greater than $2^{\circ}$ and up to $7^{\circ}$ adjacent to former ultra high pressure inclusions that have undergone multiple-phase transitions. These diamond lattice distortions adjacent to inclusions are interpreted as the result of plastic deformation and are therefore not necessarily diagnostic of a non-syngenetic origin.

In the current study, EBSD was performed on the diamond plate surface and the exposed inclusions prior to milling. EBSD patterns, formed by secondary diffraction of the elastically scattered electrons, were generated on a combined FIB-SEM instrument (FEI Nova Nanolab 600 at Utrecht University, The Netherlands) by interaction of the electron beam with the sample and recorded with a phosphor screen (Nordlys II detector, Oxford Instruments). For EBSD in the FIB-SEM, a pre-tilted holder $\left(62^{\circ}\right)$ is used and an extra tilt results in a $70^{\circ}$ angle that is ideal for EBSD. Patterns are recorded at $20 \mathrm{kV}$ electron beam acceleration voltage and $9.5 \mathrm{nA}$ beam current. Under these conditions, the spatial resolution is better than $0.5 \mu \mathrm{m}$. The crystallographic orientations were determined from the EBSD patterns using specialised software (CHANNEL 5, Oxford Instruments). 
Slice and View: micron-scale milling and $\mathrm{CL}$ and SE imaging

A new technique that leads to 3D-CL was used to study the origin of diamond inclusions (D. A. M. De Winter, M. N. Lebbink, D. F. Wiggers de Vries, M. R. Drury, Three-dimensional cathodoluminescence using FIB-SEM tomography, in preparation). This technique involves sequential milling of micron-scale slices with a FIB followed by CL imaging on each newly created surface, an approach that is called Slice and View ${ }^{\mathrm{TM}}$ (FEI Company, The Netherlands). These consecutive CL images allow a $3 \mathrm{D}$ reconstruction of the shape of the inclusion and the geometry of the diamond zonation around it because the diamond-inclusion interface and diamond zonation patterns are well preserved during slicing.

Slices with a thickness of $2 \mu \mathrm{m}$ were milled using a Ga${ }^{+}$ ion beam at $30 \mathrm{kV}$ and $7 \mathrm{nA}$ on a FEI Nova Nanolab 600 at Utrecht University, The Netherlands. The ions have an incident angle of $38^{\circ}$ in the FIB-SEM and to obtain a better CL signal, the diamond surface was tilted $10^{\circ}$ away from the ion beam during milling. Milling therefore results in surfaces with a $28^{\circ}$ angle with respect to the diamond surface. Before sequential milling, a trench was created with the ion beam in the horizontal surface of the diamond plate. Subsequent stepwise milling progresses westward in Fig. 2a and produces a widening of the trench, while the angles of the new surfaces on the west side remain $28^{\circ}$. The procedure resulted in milling away the surface exposure of the chromite inclusion (Fig. 2b). Slice and View was conducted over a length of $\sim 45 \mu \mathrm{m}$ with the removal of 23 slices. It was estimated based on the transmitted light images that only a small portion $(<20 \%)$ of the chromite inclusion has been milled.

Secondary electron (SE) imaging and CL imaging were performed perpendicular to the diamond surface and

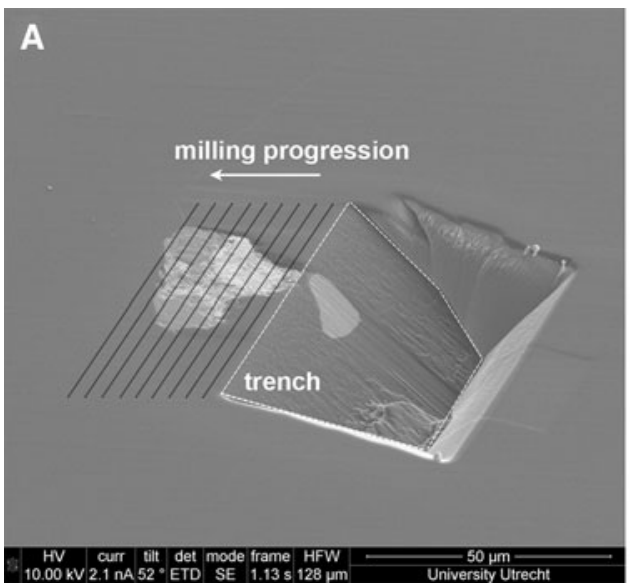

Fig. 2 a Image of the diamond plate surface that shows the trench that was milled on the FIB-SEM instrument. The trench has inclined surfaces. The inclined surface that is outlined by a white dashed line exposes part of the chromite inclusion at depth (chr-3 in Figs. 1B, 4E, required a backward rotation of $10^{\circ}$ towards zero-stage tilt. The imaging was undertaken at $10 \mathrm{kV}$ for best contrast. Note that all images are inclined, since the milled surfaces have a $28^{\circ}$ angle with respect to the horizontal diamond surface.

\section{$3 D$ reconstruction}

The consecutive images are used to make a 3D reconstruction of the area of interest that is uncovered by milling on the FIB-SEM instrument (see De Winter et al., in preparation for details). The $3 \mathrm{D}$ representation is created by linear interpolation between the images of successive slices. Movies of the consecutive SE and CL images and of the rotating 3D reconstruction are presented as supplementary material in addition to the figures in the result section in order to provide a better representation of the 3D data set. The 3D reconstruction has not been corrected for the $28^{\circ}$ angle relative to the diamond plate surface, because the software is currently unable to completely convert the complex model. An individual representation of the final $3 \mathrm{D}$ reconstruction of the chromite geometry is presented in the supplementary material to show the corrected morphology.

\section{Electron microprobe analyses}

Analyses of the elemental impurity concentration in the diamond were determined by a Jeol JXA-8800M microprobe at the VU University Amsterdam. Analyses of Cr, $\mathrm{Fe}, \mathrm{Mg}$ and $\mathrm{Al}$ were performed at $15 \mathrm{kV}$ and $20 \mathrm{nA}$ with a $2 \mu \mathrm{m}$ spot size and $400 \mathrm{~s}$ peak count times. For mineral inclusion analyses, conditions were similar except for shorter count times, $25 \mathrm{~s}$. The EMP detection limits $(3 \sigma)$ are $31 \mathrm{ppm}$ for $\mathrm{Cr}, 42 \mathrm{ppm}$ for $\mathrm{Fe}, 16 \mathrm{ppm}$ for $\mathrm{Mg}$ and

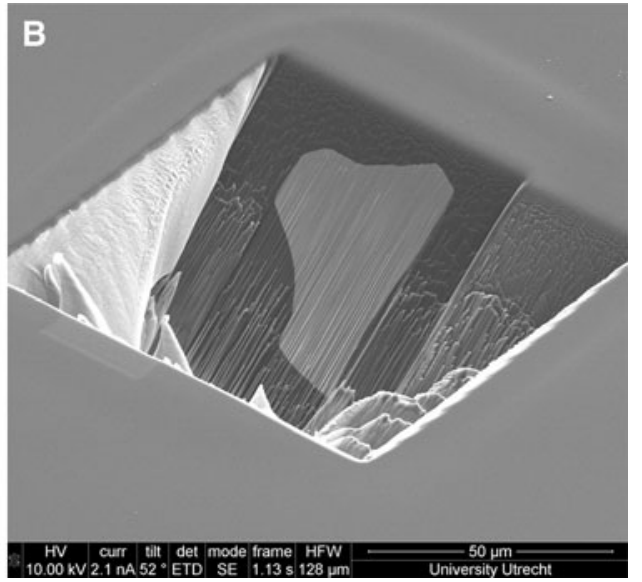

$4 \mathrm{~F})$. The black dashed lines give an impression of the course of the subsequent milling steps. b Overview of the result after 23 milling steps. (Note figures $\mathbf{a}$ and $\mathbf{b}$ are rotated w.r.t. each other and other figures to provide a better overview) 
$11 \mathrm{ppm}$ for $\mathrm{Al}$. The standards used are olivine, corundum, ilmenite, $\mathrm{Cr}_{2} \mathrm{O}_{3}$, quartz, diopside, $\mathrm{NiO}$ and ilmenite, and data are corrected following standard procedures outlined in Reed (2005).

\section{Results}

Diamond characteristics

\section{CL: internal structure of the diamond}

Most of the volume of diamond \#3615 is characterised by octahedral growth. CL imaging of the central plate reveals that the diamond crystal has two distinctive nucleation centres: a cubo-octahedral core on the left-hand side and a cubic core on the right-hand side (Fig. 1a). The two cores act as a single seed for crystallisation of the intermediate and rim areas (Fig. 1a) and explain the diamond's elongated external shape. Within the cubic core, there is an inner core zone (Fig. 1b), which has cubic symmetry and has light blue CL. Both the cubic outer core zone of the cubic core and the cubooctahedral core have yellow luminescence. Each core is surrounded by a light blue luminescent layer $(\sim 10 \mu \mathrm{m}$ thick, Fig. 1b). The intermediate area of the crystal has light blue luminescence and is characterised by octahedral zonation. The octahedral rim area has blue luminescence and slip lines, which occur over an area of $0.2 \mathrm{~mm}$ width at the edge of the crystal, have yellow CL. CL imaging establishes that there are no healed cracks in the diamond ruling out that the inclusion was formed or modified after diamond formation. The inclusions therefore have a primary nature, and an epigenetic origin is excluded. Consequently, the key question of the current study is to ascertain if the inclusions have a protogenetic or syngenetic origin with respect to the diamond host.

\section{FTIR: nitrogen content and mantle residence time}

A FTIR traverse was performed across the diamond from the cubic core towards the edge of the crystal (Fig. 1c). These data demonstrate that differences in nitrogen abundance and nitrogen aggregation state correlate with the three major zones that are observed with CL imaging.

The spectral analyses reveal a stepwise decrease in nitrogen concentration from the core towards the rim zone (Fig. 3a). The cubic core contains $360 \pm 72$ ppm nitrogen, the intermediate area has $265 \pm 53 \mathrm{ppm}$ nitrogen, and the rim zone has $20 \pm 4$ ppm nitrogen (Fig. 3a). The degree of nitrogen aggregation correlates with these spatial variations, $31 \pm 5 \%$ IaB nitrogen aggregation in the core, $25 \pm 5 \% \mathrm{IaB}$ aggregation in the intermediate, and the rim is type IaA diamond ( $\sim 0 \% \mathrm{IaB}$ aggregation) (Fig. 3a).
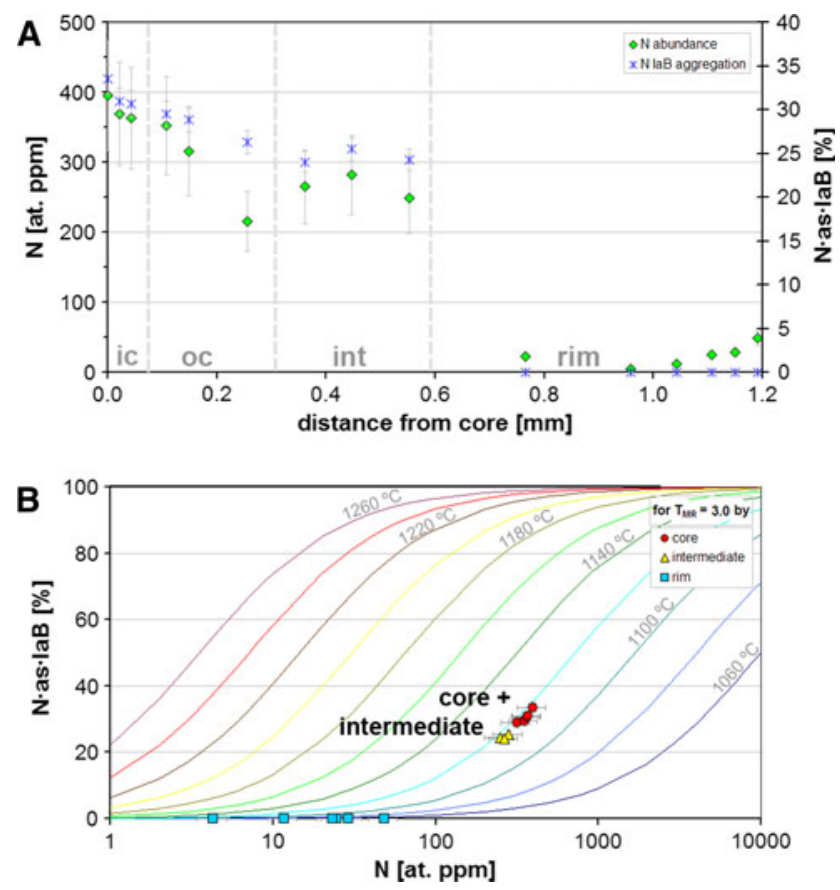

Fig. 3 a Core-rim traverse of the nitrogen concentration and the percentage of nitrogen in the $\mathbf{b}$ aggregated form in the diamond. The rim area has markedly different nitrogen characteristics. b Theoretical isotherms calculated from the FTIR spectral data assuming a mantle residence time of $3 \mathrm{Ga}$ (see explanation in text). Data points from the core and intermediate areas are shown to plot approximately on the same isotherm, while the rim is significantly different and most likely younger

Theoretical isotherms were calculated for diamond \#3615 from the nitrogen concentrations and aggregation states assuming a mantle residence time for Udachnaya diamonds of $3 \mathrm{Ga}$. This residence time is based on the difference in age between kimberlite emplacement ( 360 Ma; Kinny et al. 1997; Pearson et al. 1997) and Os model ages of sulphide inclusions in diamonds from the Udachnaya kimberlite that are 3.1-3.5 Ga (Pearson et al. 1999). Samarium-Nd model ages for garnets in Udachnaya diamonds with mantle storage temperatures of 1,100 $1,200^{\circ} \mathrm{C}$ also suggest $\mathrm{Ga}$ mantle residence times $(\sim 2.0 \mathrm{Ga}$; Richardson and Harris 1997). Nitrogen aggregation in diamond \#3615 is isothermal for the core and intermediate areas (Fig. 3b) and suggests that the core and intermediate of the diamond have comparable mantle residence times. The isotherm of the core and intermediate areas approximates to $1,120^{\circ} \mathrm{C}$. If a shorter mantle residence time of $1.6 \mathrm{Ga}$ is assumed based on $2 \mathrm{Ga}$ Udachnaya age of Richardson and Harris (1997), the nitrogen aggregation temperature approximates to $1,135^{\circ} \mathrm{C}$. The FTIR spectra of the rim area, however, do not allow accurate time/temperature deconvolution because of the low nitrogen aggregation state (Fig. 3). The rim zone therefore appears to have a significantly different mantle residence history to 
the core and intermediate zones due to either less efficient aggregation due to low nitrogen content or later formation (Taylor et al. 1990).

\section{Birefringence}

An optical study of the diamond plate reveals complex anomalous birefringence (ABR). Both rectilinear and curved patterns are visible (Fig. 1c). These patterns are the combined result of plastic deformation, dislocations, impurities (sub-micron-scale as well as larger mineral inclusions) and local fractures (Lang 1967). The ABR image reveals the major zones of diamond \#3615: both cores and linear contact between the intermediate area and the rim area are visible. In addition, smaller-scale radial ABR patterns occur around the included minerals that appear cross-shaped (e.g., Fig. 4b, d). These strain birefringence haloes (pressure haloes) extend to at least $100 \mu \mathrm{m}$ into the diamond.

Mineral inclusions and CL haloes

\section{Mineral inclusions}

At least 30 mineral inclusions with sizes that range between 5 and $150 \mu \mathrm{m}$ are hosted by the diamond (Fig. 1). Most inclusions are present within the two cores. The cubic outer core contains the largest number of inclusions (Fig. 1d). Five inclusions are exposed on the polished surface, of which four inclusions are located in the cubic core and one nearby in the intermediate diamond zone (Fig. 1). The exposed inclusions were examined in detail to select one for a 3D micron-scale study of the nature of the surrounding diamond growth layers. The inclusions occur on both sides of the plate and on an off-cut and are chromites, olivines, phlogopite and sulphide (Table 1). The phlogopite is not a secondary mineral, and its chemical composition corresponds with P-type phlogopite inclusions from diamonds that are reported to be syngenetic (Sobolev et al. 2009). A previous investigation of the chromites in diamond \#3615 recorded a gradual change in their chemistry from the core to the rim of the diamond. The $\mathrm{Mg} \#$ $[\mathrm{Mg} /(\mathrm{Mg}+\mathrm{Fe})]$ decreases from 0.62 to 0.58 , and the $\mathrm{Cr} \#$ $[\mathrm{Cr} /(\mathrm{Cr}+\mathrm{Al})]$ increases from $0.82-0.85$ to 0.89 (Table 1 ). This compositional evolution was interpreted as a record of crystallisation from a melt or fluid that was cooling and fractionating olivine and pyroxene (Bulanova 1995). Trace element abundances in the chromite and olivine inclusions in diamond \#3615 were studied by proton microprobe (Table 1), and the crystallisation temperatures of the chromites were subsequently determined by zinc geothermometry following Griffin et al. (1993a, b). The Ga concentrations range between 9 and $23 \mathrm{ppm}$, which is typical
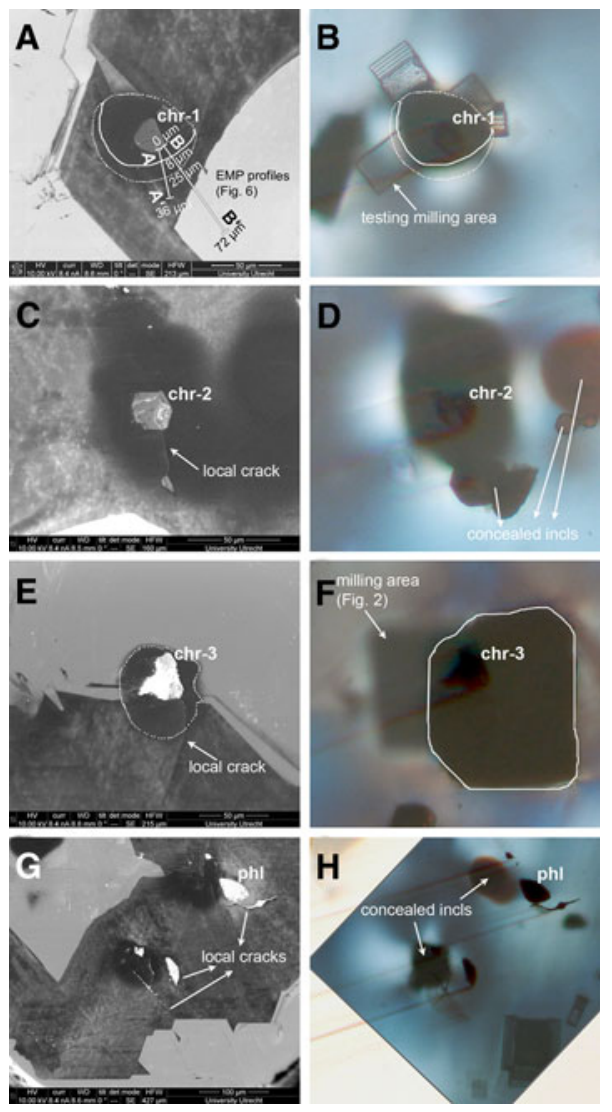

Fig. 4 Mixed CL-SE images (left row) and mixed birefringencetransmitted light images (right row) of the five exposed mineral inclusions from Fig. 1. The CL images reveal the existence of $\mathrm{CL}$ haloes around inclusions (see explanation in text). The CL haloes do not correlate with the cross-shaped strain birefringence haloes as the sizes of the haloes are different. Transmitted light images reveal that a substantial part of the inclusions is concealed at depth (e.g., its contour is indicated by the white line for chr-1 and chr-3). The CL halo, indicated by the white dotted line for chr-1 and chr-3, does not follow with the outline and size of these (concealed) inclusions. The exposed inclusions are partly covered with remains of conductive coating material and locally surface cracks, and NE-SW running grooves associated with the inclusions were created during polishing as the inclusions are insufficiently resistant to the diamond polishing process. a-f All three exposed chromite inclusions are associated with a CL halo. $\mathrm{AA}^{\prime}$ and $\mathrm{BB}^{\prime}$ are EMP traverses of $\mathrm{Cr}$ and $\mathrm{Fe}$ content (Fig. 6). $\mathbf{g}-\mathbf{h}$ The exposed non-chromite inclusions are not surrounded by a CL halo, but the nearby CL haloes are associated with concealed inclusions

for chromites in Udachnaya diamonds (Griffin et al. 1993b). The contents of $\mathrm{Sr}, \mathrm{Y}, \mathrm{Zr}$ and $\mathrm{Nb}$ in the inclusions are very low and close to detection limit. The Ni concentration in the chromites decreases, i.e., for chromites positioned from the core to the rim of the diamond, from 785-660 to $625 \mathrm{ppm}$, while the $\mathrm{Zn}$ concentrations increase accordingly from 435-469 to $557 \mathrm{ppm}$. In correspondence with the gradual change in $\mathrm{Zn}$ concentrations, the formation temperatures of the chromites decrease from 1,1261,158 to $1,058^{\circ} \mathrm{C}$ from the core to the rim of the diamond. 
Table 1 Major and trace element concentrations of the exposed mineral inclusions

\begin{tabular}{|c|c|c|c|c|c|c|c|}
\hline \multirow{2}{*}{$\begin{array}{l}\text { Location } \\
\text { Mineral }\end{array}$} & \multicolumn{4}{|l|}{ Core } & \multirow{2}{*}{$\begin{array}{l}\text { Core/intermediate } \\
\text { chr-3 }\end{array}$} & \multicolumn{2}{|l|}{ Rim } \\
\hline & chr-1 & ol & chr-2 & phl & & $\mathrm{chr}$ & ol \\
\hline \multicolumn{8}{|l|}{ EMP [wt\%] } \\
\hline $\mathrm{SiO}_{2}$ & 0.14 & 41.13 & 0.16 & 42.3 & 0.48 & 0.71 & 40.12 \\
\hline $\mathrm{TiO}_{2}$ & 0.02 & 0 & 0.02 & 0.1 & 0 & 0 & 0 \\
\hline $\mathrm{Al}_{2} \mathrm{O}_{3}$ & 7.28 & 0 & 8.8 & 10.57 & 7.08 & 5.2 & 0 \\
\hline $\mathrm{Cr}_{2} \mathrm{O}_{3}$ & 61.48 & 0.2 & 59.99 & 1.73 & 62.75 & 65.59 & 0.01 \\
\hline $\mathrm{FeO}$ & 15.23 & 7.21 & 15.55 & 3.3 & 17.33 & 17.85 & 7.54 \\
\hline $\mathrm{MnO}$ & n.a. & 0 & n.a. & 0 & 0.1 & 0.08 & 0 \\
\hline $\mathrm{MgO}$ & 12.39 & 52.67 & 12.58 & 26.84 & 12.26 & 12.13 & 52.75 \\
\hline $\mathrm{NiO}$ & 0.04 & n.a. & 0.05 & n.a. & n.a. & n.a. & n.a. \\
\hline $\mathrm{CaO}$ & 0 & 0 & 0 & 0.08 & 0 & 0 & 0 \\
\hline $\mathrm{Na}_{2} \mathrm{O}$ & 0 & 0 & 0 & 0 & 0 & 0 & 0 \\
\hline $\mathrm{K}_{2} \mathrm{O}$ & 0 & 0 & 0 & 9.8 & 0 & 0 & 0 \\
\hline Total & 96.58 & 101.21 & 97.15 & 94.72 & 100 & 101.56 & 100.42 \\
\hline $\mathrm{Mg} / \mathrm{Mg}+\mathrm{Fe}$ & 0.619 & 0.929 & 0.626 & & 0.594 & 0.578 & 0.926 \\
\hline $\mathrm{Cr} / \mathrm{Cr}+\mathrm{Al}$ & 0.850 & & 0.821 & & 0.858 & 0.895 & \\
\hline \multicolumn{8}{|l|}{ PMP [ppm] } \\
\hline $\mathrm{Ni}$ & $625 \pm 66$ & $2880 \pm 300$ & $784 \pm 82.4$ & n.a. & $659 \pm 69$ & $660 \pm 36$ & n.a. \\
\hline $\mathrm{Zn}$ & $469 \pm 34$ & $38 \pm 3$ & $435 \pm 33$ & n.a. & $511 \pm 36$ & $557 \pm 44$ & n.a. \\
\hline $\mathrm{Ga}$ & $13.4 \pm 2.6$ & $<$ d.l. & $8.6 \pm 2.8$ & n.a. & $11.1 \pm 2.5$ & $23.4 \pm 4$ & n.a. \\
\hline $\mathrm{Sr}$ & $2.2 \pm 1.6$ & $<$ d.l. & $6.67 \pm 1.8$ & n.a. & $1.46 \pm 1.1$ & $<$ d.l. & n.a. \\
\hline $\mathrm{Y}$ & $1.77 \pm 1.5$ & $<$ d.l. & $<$ d.l. & n.a. & $2.6 \pm 1.1$ & $<$ d.1. & n.a. \\
\hline $\mathrm{Zr}$ & $1.72 \pm 1.5$ & $<$ d.l. & $<$ d.l. & n.a. & $3.0 \pm 1.1$ & $<$ d.l. & n.a. \\
\hline $\mathrm{Nb}$ & $4.73 \pm 1.7$ & n.a. & $7 \pm 2$ & n.a. & $1.83 \pm 1.4$ & $<$ d.l. & n.a. \\
\hline$T_{\mathrm{Zn}}\left({ }^{\circ} \mathrm{C}\right)$ & $1126 \pm 30$ & & $1158 \pm 30$ & & $1091 \pm 30$ & $1058 \pm 30$ & \\
\hline
\end{tabular}

n.a. not analysed, d.l. detection limit, $T_{Z n}$ Zinc thermometry

The results of chromite Zn-thermometry are in good agreement with nitrogen aggregation temperatures for diamond \#3615 obtained by FTIR and suggest that the diamond and the inclusions may have formed simultaneously (Fig. 3, Table 1).

\section{Diamond CL haloes around chromite inclusions}

Areas of diamond immediately around some inclusions $(2-30 \mu \mathrm{m})$ are non-luminescent (Figs. 1b, 4). This characteristic is not visible using standard microscopy. It is manifested as a CL "dark zone" associated with the inclusions. We will refer to these non-luminescent zones in the diamond as CL haloes. Energy-dispersive X-ray analyses confirm that CL haloes consist of diamond, and hence, its non-luminosity is not the direct result of the presence of non-luminescent silicate or chromite inclusions.

A more detailed investigation establishes that only the chromite inclusions in our study have a CL halo (Figs. 1b, 4). Apparent CL haloes close to phlogopite (Figs. 1b, 4g, 4h) are related to concealed chromite inclusions at depth. Figures $1 \mathrm{~d}$ and 4 show the inclusions in transmitted light and reveal their shape at depth. In some cases, inclusions are larger at depth than their surface exposure; however, there is no direct correlation between the size of the chromite inclusion and the shape of the corresponding CL halo. The outline of the CL halo around chromite- 2 matches the contour of the concealed chromite; however, the CL halo associated with chromite- 3 is far smaller than the dimensions of the inclusion at depth, and the CL halo associated with chromite-1 is larger than the inclusion geometry at depth (Fig. 4). The size and shape of the CL haloes do not correspond with the significantly larger pressure haloes described earlier (Sect. 4.1.3; Fig. 4). The birefringence associated with the inclusions is accumulated from depth in the diamond plate and so is not expected to directly correspond to the CL image derived from the surface alone (Izraeli et al. 1999; Nasdala et al. 2005). It appears that the CL haloes are mostly irregularly shaped with both well-defined straight and diffuse margins (Figs. 4, 5). The well-developed margins of the CL halo that surround chromite-3 form symmetrically oriented pointed features and give the halo an apparent crystallographic morphology (Fig. 5). A further more detailed 


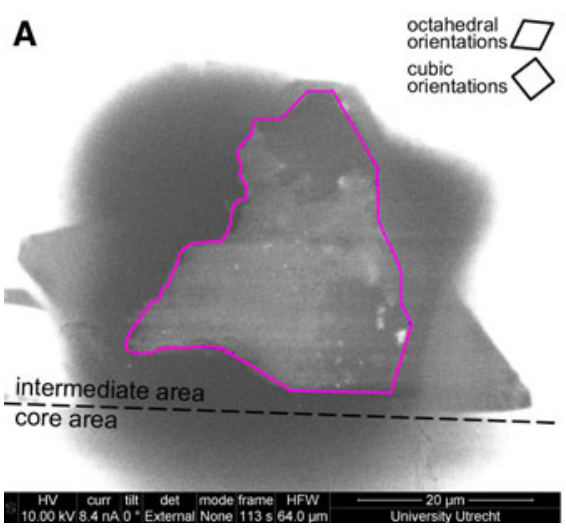

Fig. 5 Mixed CL-SE image of chromite inclusion (chr-3) from Fig. 1 near the core-intermediate boundary before milling (a), where the chromite is outlined in pink and partly covered by a conductive coating material, and after milling (b). The chromite is surrounded by

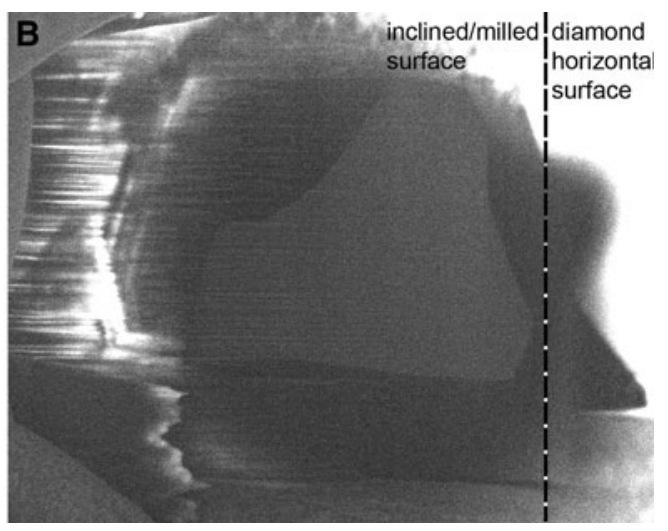

a diamond CL halo with an apparent crystallographic morphology with symmetrically oriented pointed features. The CL halo obscures the CL characteristics of the diamond's core-intermediate boundary and appears to crosscut this contact description of the CL halo around chromite- 3 is presented in Sect. 4.4.2.

Electron microprobe traverses were conducted across the CL halo of chromite-1 (Figs. 4a, 6) to determine the abundances of $\mathrm{Cr}, \mathrm{Fe}, \mathrm{Mg}$ and $\mathrm{Al}$, the main elements in chromite. From a study of the transmitted light images, it was established that EMP analyses of this CL halo do not sample the concealed chromite once the electron beam was more than $8 \mu \mathrm{m}$ away from the diamond-chromite contact at the sample surface and that the CL halo extends to a distance of $\sim 25 \mu \mathrm{m}$ from the diamond-chromite interface (Fig. 4a, b). The EMP traverses establish that $\mathrm{Cr}$ and $\mathrm{Fe}$ are incorporated in the crystal lattice of the diamond CL halo (Fig. 6) but $\mathrm{Mg}$ and $\mathrm{Al}$ levels are below EMP detection limits (Table 2). The $\mathrm{Cr}$ and $\mathrm{Fe}$ contents decrease asymptotically (note log scale in Fig. 6) from within the chromite outwards to $140 \mathrm{ppm}$ and below detection limits, respectively (detection limits are 31 and $42 \mathrm{ppm}$, respectively). Estimated $\mathrm{Cr}$ and $\mathrm{Fe}$ levels in the $\mathrm{CL}$ halo are $\sim 200$ and $\sim 80 \mathrm{ppm}$, respectively (Fig. 6). The presence of $\mathrm{Fe}$ is known to subdue CL (Pagel et al. 2000) and together with the presence of $\mathrm{Cr}$ can explain the non-luminescent character of the CL haloes around the inclusions. The normal luminescent diamond area within a radius of $\sim 200 \mu \mathrm{m}$ around chromite- 3 also has elevated levels of $\mathrm{Cr}$ and $\mathrm{Fe}$ (i.e., Fig. 6 and analyses 8-10 in Table 2). The content of these impurities is $\sim 50-150 \mathrm{ppm}$ (with one outlier of $271 \mathrm{ppm}$ Cr, Table 2) and 20-75 ppm, respectively. These concentrations, however, are generally lower than in the CL halo associated with chromite-1 and appear insufficient to induce a CL halo. Cr and Fe levels in all other parts of the diamond are below EMP detection limits (see Table 2).
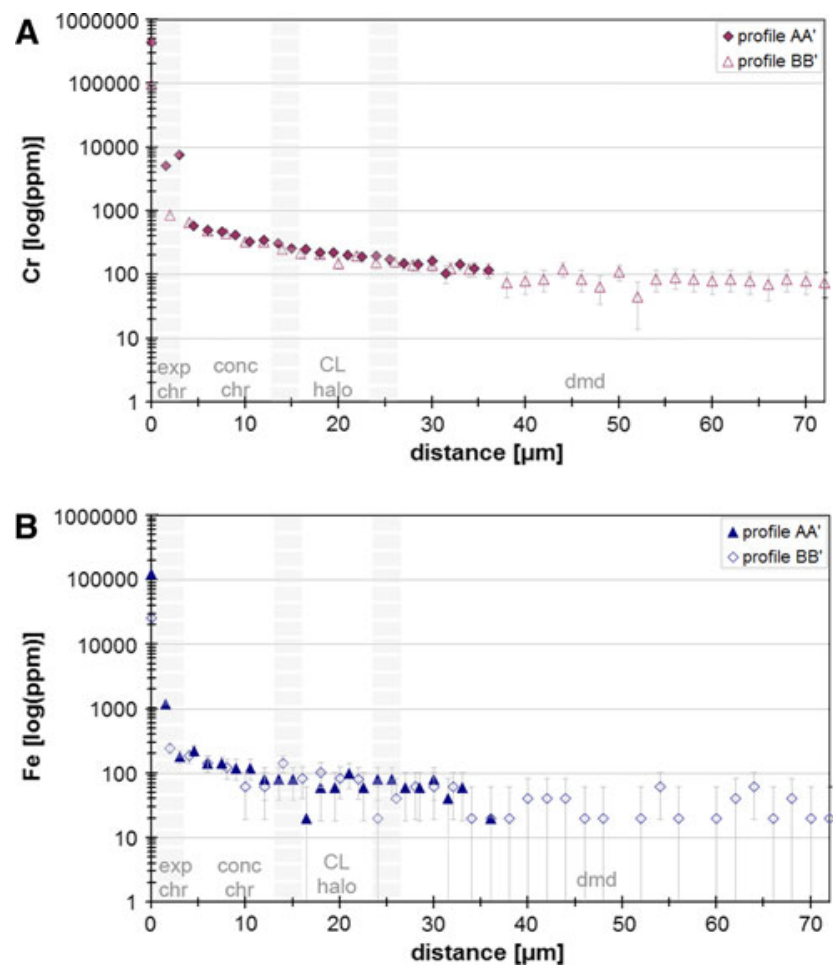

Fig. 6 EMP traverses of the $\mathrm{Cr}$ and $\mathrm{Fe}$ levels away from chromite-1 along profiles $\mathrm{AA}^{\prime}$ and $\mathrm{BB}^{\prime}$ in Fig. $4 \mathrm{~A}$. The traverses intersect the chromite inclusion, the CL halo and the diamond. exp.chr. = exposed chromite, conc.chr. $=$ concealed chromite. The interaction depth of EMP analyses is $1.8-1.9 \mu \mathrm{m}$, and it thus averages elemental contents throughout the area of interest. The grey dashed areas indicate the interaction volumes between the different regions. The step size along profile $\mathrm{AA}^{\prime}$ is $1.5 \mu \mathrm{m}$ and along $\mathrm{BB}^{\prime}$ is $2.0 \mu \mathrm{m}$. a The CL halo has $\mathrm{Cr}$ levels of $\sim 200 \mathrm{ppm}$, and the surrounding diamond has $\mathrm{Cr}$ levels of $\sim 140 \mathrm{ppm}$. b The CL halo contains $\sim 80 \mathrm{ppm} \mathrm{Fe}$, while the levels in the surrounding diamond are below detection limits 
Table 2 Major element concentrations in the diamond

\begin{tabular}{lllll}
\hline & $\mathrm{Mg}(\mathrm{ppm})$ & $\mathrm{Al}(\mathrm{ppm})$ & $\mathrm{Cr}(\mathrm{ppm})$ & $\mathrm{Fe}(\mathrm{ppm})$ \\
\hline 1. & $<$ d.1. & $<$ d.1. & $<$ d.1. & $<$ d.1. \\
2. & $<$ d.1. & $<$ d.1. & 34 & $<$ d.1. \\
3. & $<$ d.1. & $<$ d.1. & $<$ d.1. & $<$ d.1. \\
4. & $<$ d.1. & $<$ d.1. & $<$ d.1. & $<$ d.1. \\
5. & $<$ d.1. & $<$ d.1. & 49 & $<$ d.1. \\
6. & $<$ d.1. & $<$ d.1. & $<$ d.1. & $<$ d.1. \\
7. & $<$ d.1. & $<$ d.1. & 34 & $<$ d.1. \\
8. & $<$ d.1. & $<$ d.1. & 118 & 99 \\
9. & $<$ d.1. & $<$ d.1. & 271 & 100 \\
10. & $<$ d.1. & $<$ d.1. & 79 & $<$ d.1. \\
\hline
\end{tabular}

The data points are indicated in Fig. 1a, c. d.1. = detection limit (16 ppm for $\mathrm{Mg}, 11 \mathrm{ppm}$ for $\mathrm{Al}, 31 \mathrm{ppm}$ for $\mathrm{Cr}$ and $42 \mathrm{ppm}$ for $\mathrm{Fe}$ )

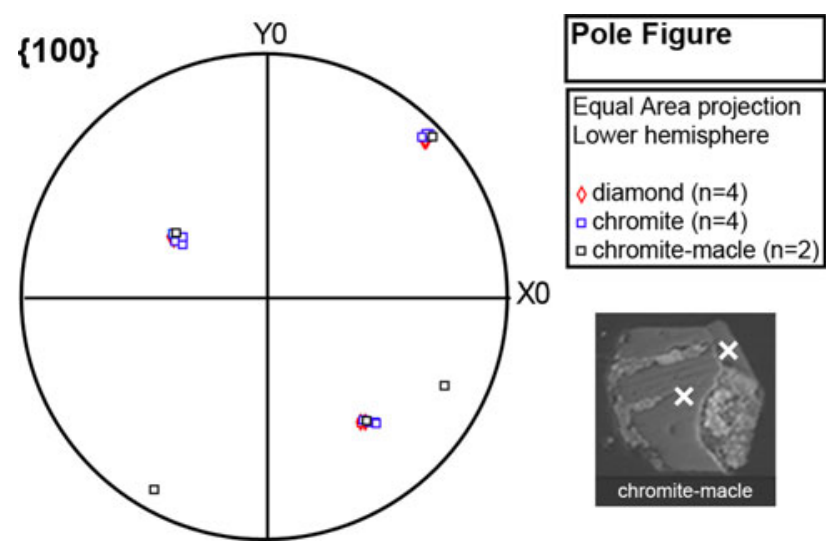

Fig. $7\{100\}$ pole figure of the EBSD orientations of diamond and the three exposed chromite inclusions (chromites 1-2-3 in Fig. 1). The [100] crystallographic directions of the diamond are parallel to the [100] directions of the chromites (within 0.4 of a degree). Chromite- 2 is a bi-crystal (a chromite macle) as the left part of this inclusion (see inset) has the same orientation as the diamond, while the right part of the chromite is rotated by $27^{\circ}$

Electron backscatter diffraction: diamond and inclusions

Electron backscatter diffraction was performed on the diamond and chromites to quantitatively determine the crystallographic orientation of the host diamond, the diamond CL haloes and mineral inclusions. The exposed surfaces of the other inclusions were insufficiently level and intact to obtain reliable EBSD patterns. Figure 7 presents the $\{100\}$ pole figures of the scanned diamond and chromite surfaces and demonstrates that their [100] crystallographic directions are parallel within an error of $\pm 0.4^{\circ}$. One of the chromites appears to be a spinel macle, as it displays two different orientations: its left part has the same orientation as the diamond, while its right-hand side is rotated $\sim 27^{\circ}$.
Slice and View: micron-scale milling and CL imaging

\section{Chromite-3}

Secondary electron imaging and CL imaging prior to milling demonstrate that the surface exposure of the chromite inclusion is situated next to the diamond's coreintermediate boundary (Figs. 1b, 4e). The exposed part of the chromite is $\sim 30 \mu \mathrm{m}$ wide. The majority of the chromite inclusion is concealed within the diamond and is up to $\sim 100 \mu \mathrm{m}$ in diameter (Fig. 4f). From transmitted light imaging, it appears that less than $20 \%$ of the chromite has been exposed by milling. The same image also reveals that there is a non-luminescent diamond CL halo surrounding the chromite. Figure 5 shows the chromite inclusion and surrounding halo before and after milling.

Figure 8 presents five representative SE and CL images of the 23 newly created surfaces during Slice and View performed on the FIB-SEM instrument. The complete set of SE and CL images is presented in movies in the electronic supplementary material 1 and 2, respectively. The outline of the chromite, the margin of the CL halo and the configuration of diamond growth layers are indicated in the figure with different colours to aid visibility. Stepwise milling reveals that the chromite has a complex morphology with numerous small faces that have different orientations. The chromite's principal faces define octahedral and cubic orientations. This multi-faced morphology is uncommon for a chromite mineral crystallising in an unrestricted environment.

\section{Diamond CL halo}

A diamond CL halo surrounds the chromite- 3 inclusion and crosscuts the diamond's core-intermediate contact (Fig. 4e). CL imaging during milling reveals that the CL halo is also present at depth and continues to obscure the diamond's core-intermediate contact (Fig. 5). The CL halo has octahedral and cubic margins; however, its shape does not exactly match the geometry of the chromite inclusion (Figs. 4e, 5). The CL halo has a complex geometry with both diffuse and sharp margins. The well-developed margins of the CL halo form symmetrically oriented pointed features and give the halo an apparent crystallographic morphology. The CL halo has a variable thickness (from 2 to $30 \mu \mathrm{m})$ as its margins are not always parallel to the chromite faces. The CL halo is thickest on the northwest side of the chromite, i.e., at position $\mathrm{X}$ in Fig. 8j. The margins of the halo change orientation with depth. Progressively milling through the well-defined pointed feature on the west side also demonstrates that the pointed feature consists entirely of diamond. Depending on the CL imaging contrast, it may be hard to distinguish between the 


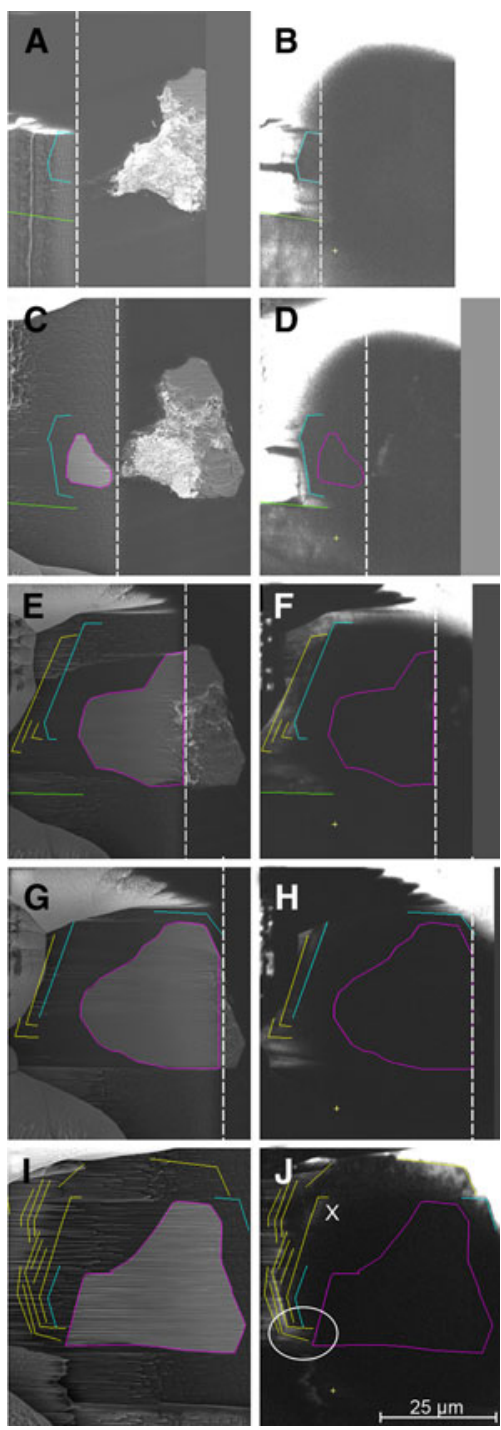

Fig. 8 Consecutive SE images (left row) and CL images (right row) of milling steps 6,10,14, 17 and 23, respectively (out of 23 steps), of the chromite inclusion (chr-3) from Fig. 1. The complete set of SE and CL images is presented by means of a movie (electronic supplementary material 1 and 2, respectively). The dashed white line indicates the contact between the inclined milling surface and the horizontal $\{110\}$ surface of the diamond. The images are taken perpendicular to the diamond surface. The pink lines mark the outline of the chromite inclusion exposed in the trench, the green lines indicate the diamond's core-intermediate boundary, the light blue lines outline the sharp margins of the CL halo, and the yellow lines indicate diamond growth layers. The diffuse margins of the CL halo are not indicated in colour. The $\mathrm{X}$ in image $\mathbf{j}$ marks the thickest part of the diamond CL halo. The $\mathrm{O}$ in image $\mathbf{j}$ illustrates diamond growth layers overprinting each other and growth layers that intersect the chromite grain boundary. The image is slightly distorted by curtaining (see text), and there is redeposition at the base of the inclined milling surface (i.e., on the left side of the chromite)

diamond CL halo and the diamond core area and between the CL halo and the diamond growth layer parallel to the diamond core area (at the west side of the chromite in
Fig. 5). Detailed examination of the various CL images, however, establishes that the CL halo, the diamond core area and this specific growth layer are different features with distinct $\mathrm{CL}$ characteristics (i.e., at position $\mathrm{O}$ in Fig. 8 j).

\section{Micron-scale diamond growth layering}

The geometry of the diamond's core-intermediate contact adjacent chromite- 3 is masked by the diamond CL halo, and it could not be resolved whether this contact crosscuts chromite-3 or grows around it (Figs. 5, 8). Nonetheless, micron-scale diamond growth layers are revealed on the west side of chromite-3 from milling step 14 onwards (Fig. 8). These growth layers occur at the margins of the CL halo and are parallel to the outline of the halo. Diamond micron-scale growth layers are also observed on the northeast side of the chromite at the edge of the CL halo. No growth layers are identified in the core area of the diamond in the milled sections, i.e., on the south side of the chromite. The orientation and thickness of the diamond growth layers is variable, especially on the west side of the chromite where the growth layers change orientation. Individual diamond growth layers appear to be 1-3 $\mu \mathrm{m}$ thick. On the west side of the chromite (Fig. 8), the E-Woriented diamond growth layers are parallel to the coreintermediate diamond contact and intersect the chromite grain boundary. The micron-scale growth layers also frequently appear to be discontinuous and intersect each other. The E-W-oriented growth layers on the west side of the chromite, for example, appear to cut-off the NW-SE-oriented growth layers, and additionally, these NW-SE-oriented growth layers seem to crosscut NE-SW-orientated growth layers.

\section{Milling artefacts}

An artefact of the milling process is "curtaining", i.e., grooves develop in the diamond surface parallel to the milling direction due to the incoming ion beam. This effect is a consequence of the inclusion being less resistant to the ion beam than the diamond, and as a result, the diamond situated west of the chromite in Fig. 8 is preferentially milled away and horizontal grooves are produced.

\section{$3 D$ reconstruction of the chromite and surrounding diamond}

The 3D reconstruction of the chromite morphology based on the 23 individual surfaces exposed by milling through part of the inclusion is presented in Fig. 9. The inset in Fig. 9a shows the initial results of the same model but is corrected for the angle at which the CL images are taken. 
Fig. 9 3D representation of the form of the corner of the chromite inclusion at depth (chr-3) from Fig. 1 as revealed after milling. Colours of lines as in Fig. 8. a Side view and $\mathbf{b}$ Top view. Note that the $3 \mathrm{D}$ reconstruction is inclined by $28^{\circ}$ with respect to the horizontal diamond surface and the inset in a gives an impression of the corrected chromite model (see text for explanation). The 3D reconstructions are also made available as rotating movies (electronic supplementary material 3 and 4)
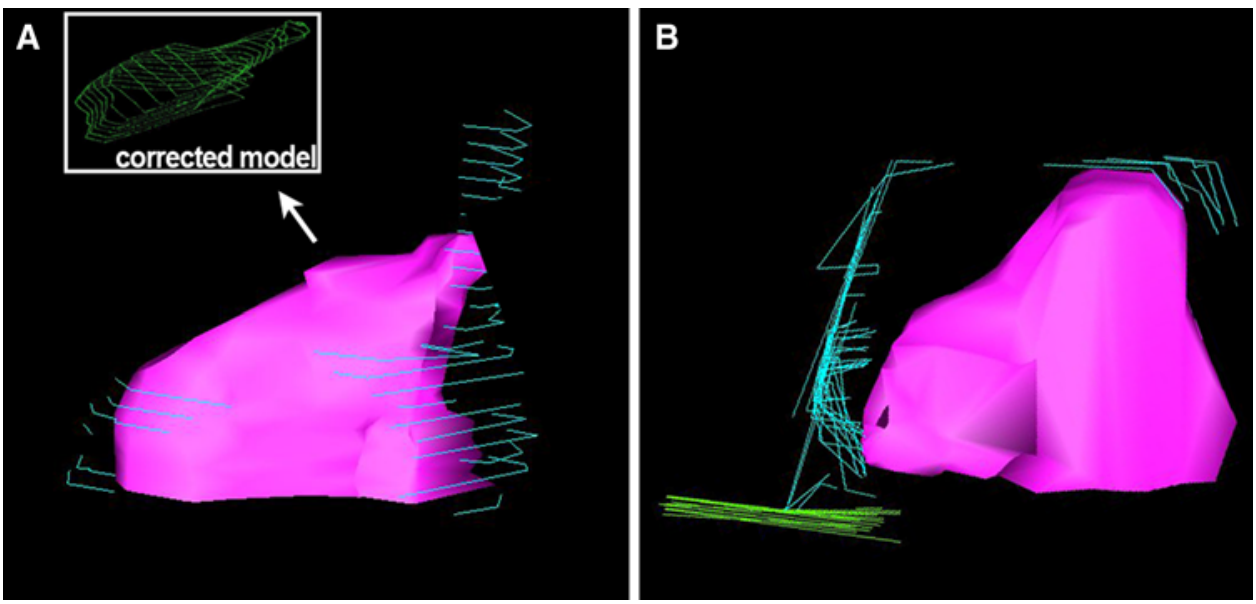

This reconstruction is therefore flatter and longer than the uncorrected model in the same figure. Rotating movies of the 3D models are available in the electronic supplementary materials 3 and 4 , respectively.

\section{Discussion}

Evaluation of the combined FIB-SEM technique applied to diamond

This study establishes that the Slice and View technique on the combined FIB-SEM instrument is capable of revealing the internal structure of diamonds by imaging individual diamond growth layers in great detail. Gallium beamrelated defects are produced by ion implantation in the upper $10 \mathrm{~nm}$ (De Winter et al., in preparation); however, these appear to have no visible effect on the CL images. Both the diamond growth layers and diamond-inclusion interface are well preserved during slicing. This technique therefore resolves micron-scale growth zonation with 3D$\mathrm{CL}$ in diamonds and can be applied to investigate the nature of micron-scale diamond growth layers to resolve the genetic origin of inclusions.

A major disadvantage of the technique is that diamond milling is time-consuming [about $30 \mathrm{~min}$ for each slice; for more detail see De Winter et al., in preparation]. Also, artificial grooves, i.e., curtaining, can appear in the milled sections because inclusions are more susceptible to the milling process than diamond.

When applying this technique, the thickness of slices should be considered carefully because CL images do not simply record the luminescence of a surface. Secondary electrons have sufficient energy to activate a volume of $<1 \mu \mathrm{m}^{3}$ around the incident spot. The dimension of the interaction volume depends on the chemistry of the sample and the acceleration voltage of the beam. Based on the observed nitrogen contents in diamond \#3615 and an operating potential of $10 \mathrm{kV}$, an area of $500 \mathrm{~nm}$ deep will luminesce. If the thickness of the slices exceeds the interaction volume, small features cannot be resolved in the z-direction. In the case of thinner slices, information in successive slices may overlap.

Genetic origin of the inclusions

The possibility of post diamond growth formation of chromite- 3 is rejected, because of the absence of healed cracks and the unlikelihood of growing such a large inclusion ( $\sim 100 \mu \mathrm{m}$ in diameter) within the diamond. The similar crystallographic orientation of the host diamond and the three chromite inclusions (Fig. 7) implies that the diamond host controlled the orientations of the inclusions, and hence, a random protogenetic origin for the inclusions seems unlikely. Also the systematic change in $\mathrm{Mg \#}$ and $\mathrm{Cr} \#$ in the chromite inclusions from diamond core to rim suggests that the inclusions crystallised from a chemically evolving melt during diamond growth (Table 1). A syngenetic origin of the inclusions with the diamond host is therefore implied.

Stepwise milling illustrates that the partially exposed chromite-3 has a complex crystallographic shape with numerous small faces that predominantly define octahedral and cubic orientations (Figs. 8, 9). This multi-faceted morphology is not a natural form of chromite crystals. This morphology implies that the chromite did not crystallise in an unrestricted environment but in the presence of other solids that hindered or controlled its morphology. It seems therefore most likely that the diamond host imposed the complex morphology upon the chromite during simultaneous growth.

An alternative model to explain the chromite morphology is that annealing or recrystallisation occurred in the short time span between chromite formation and 
entrapment by the diamond host; i.e., the cubo-octahedral morphology is secondary and imposed by the diamond to minimise the surface energy of the inclusion as diamond grows. We do not favour this model but it cannot be ruled out based on the chromite morphology alone. A posttrapping origin of the chromite's cubo-octahedral morphology contrasts with the currently accepted model that the faceting of mineral inclusions along diamond faces indicates a syngenetic origin for the inclusion (Bulanova 1995; Futergendler and Frank-Kamenetsky 1961; Harris and Gurney 1979; Meyer 1985; Meyer 1987; Mitchell and Giardini 1953; Orlov 1977; Pearson and Shirey 1999; Sobolev 1977).

Fine-scale diamond growth layers are observed in the intermediate part of the diamond but not in the diamond's core area. This observation, coupled with one face of the chromite being parallel to the core-intermediate boundary, suggests that the chromite nucleated on a diamond surface or was fortuitously trapped on the diamond surface with its face parallel to the diamond surface (Fig. 5a). Diamond growth layers generally follow the outline of the chromite, which in theory is a protogenetic feature, while other growth layers intersect the chromite, which in theory is a syngenetic feature (Fig. 8). The diamond growth layering around the chromite defines several orientations, parallel to octahedral and cubic directions that locally appear to intersect each other (Fig. 8). It is assumed that layers further away from the diamond's core-intermediate boundary are the younger, i.e., northward in Fig. 8. This implies that following the E-W-oriented diamond growth layers northward from the diamond's core-intermediate boundary, the growth direction is towards the chromite. The E-Woriented diamond growth layers close to the diamond's core-intermediate contact, however, crosscut NW-SE-oriented diamond growth layers that are closer to the chromite suggesting a reverse chronology. Hence, in this case, it appears that the geometry of diamond growth layers directly around an inclusion cannot be used to unambiguously solve the genetic origin of the chromite. The geometry of growth layers suggests that the diamond-inclusion relationship is complex and raises the possibility that diamond and chromite growth may have been, at least partially, contemporaneous and that diamond may have nucleated on both the chromite inclusion and diamond faces after trapping the mineral.

We interpret this complex growth morphology as a consequence of diamond nucleation on the chromite crystal faces leading to diamond growth in several directions whereby direction-dependent growth rates and/or different growth rates of diamond and chromite complicate the geometry of the diamond growth layering. Following this line of reasoning, it becomes somewhat semantic to ascribe a syn- or protogenetic origin to the inclusion. The implication is that in the early phases of growth of the diamond's intermediate area, the chromite started to crystallise upon the diamond as a syngenetic inclusion and that during subsequent growth, the chromite was essentially a protogenetic phase as a result of different growth rates whereby the chromite grew faster and the diamond nucleated relatively late around it.

Interpretation of the diamond CL halo

The presented images clearly establish that the CL haloes are not directly related to the inclusion morphology or their pressure haloes (Fig. 4). High-voltage particle beams ( $\mathrm{MeV}$ range) are known to create defects in diamond (Palmer 1994). Diamond CL spectra have occasionally been reported to intensify under the influence of electron beams of $20 \mathrm{kV}$, most likely as a result of charging of existing defect structures (Kanda and Watanabe 2006; Kanda et al. 2005). These authors show rectangular, linear or spotty regions with brighter CL that are the direct result of irradiation. However, this effect is opposite to the features in the current diamond where the CL halo is nonluminescent. Moreover, the CL halo is not an artefact of the conducted analyses nor FIB milling, as it was present in the diamond before the combined FIB-SEM study (Figs. 1b, 4e, 5a).

CL haloes associated with inclusions in diamonds have been previously reported surrounding garnet and olivine inclusions (Anand et al. 2004; Appleyard et al. 2004; Promprated et al. 2004; Taylor and Anand 2004) but were not studied in detail. The CL images presented here (Figs. 1, 4) establish that CL haloes are non-luminescent areas associated with chromite inclusions. Appleyard et al. (2004) and Milledge et al. (1989) proposed that the Al in garnet inclusions has the effect of "gettering" or sequestering nitrogen from the diamond, and this results in the formation of non-luminescent type II diamond with low to undetectable nitrogen contents $(<10 \mathrm{ppm})$. This observation has not been supported by any measurements of enhanced nitrogen concentration in the lattices of garnets.

Elemental concentrations of the most common light elements in diamond (e.g., $\mathrm{Fe}, \mathrm{Si}, \mathrm{Mg}, \mathrm{Al}$ and $\mathrm{Ca}$ ) are typically $1-100 \mathrm{ppm}$, and $\mathrm{Cr}$ is reported to be maximum 2 ppm (Fesq et al. 1975; Raal 1957). Fesq et al. (1975) showed that these impurities are generally associated with small cracks and inclusions and the actual concentrations in the diamond crystal lattice are most probably lower. The presence of $\mathrm{Cr}$ and $\mathrm{Fe}$ in the diamond $\mathrm{CL}$ halo ( $\sim 200$ and $\sim 80$ ppm, respectively; Fig. 6) is therefore relatively high and can explain the non-luminescent character of the $\mathrm{CL}$ halo (Pagel et al. 2000).

Establishing the process responsible for CL halo formation requires knowledge of the time of their formation, 
i.e., are CL haloes primary growth features or do they represent secondary effects. A pertinent observation is that the CL halo around the chromite crosscuts a major growth boundary in the diamond (Figs. 1b, 4e), suggesting that the $\mathrm{CL}$ haloes have a secondary origin. Chrome and $\mathrm{Fe}$ are the two most common elements in chromites, and hence, it is suggested that these elements originate directly from the chromite and not from the diamond/chromite-forming melt or fluid. Therefore, it seems most likely that $\mathrm{Cr}$ and $\mathrm{Fe}$ were incorporated in the diamond crystal lattice after chromite formation.

Dissolution-chemical annealing, i.e., secondary precipitation, is reported to form CL haloes within quartz and within zircons and plagioclases with oscillatory zonation (Pidgeon 1992; Van den Kerkhof and Hein 2001; Van den Kerkhof et al. 2004; Vance 1965). These CL haloes are interpreted to have formed in situ around fluid inclusions or due to infiltration channelling of melts along major crystal defects such as cracks and impurities. Dissolution-chemical annealing requires the presence of water. Diamond-forming fluids are reported to be water-rich (Klein-BenDavid et al. 2007; Navon et al. 1988; Schrauder and Navon 1994), and evidence for a hydrous nature for diamond \#3615 is the phlogopite inclusion in the core area (Fig. 1). FTIR spectroscopy across the diamond plate revealed no peaks associated with water or microscopic hydrous inclusions, besides hydrogen defect centres at $3,107 \mathrm{~cm}^{-1}$. Therefore, a dissolution-chemical annealing process cannot be ruled out based on the current data.

Perhaps the most simple process to form diamond $\mathrm{CL}$ haloes around chromite inclusions is through $\mathrm{Cr}$ and $\mathrm{Fe}$ diffusion, although the occurrence and transport of atoms that are larger than carbon in the diamond crystal is particularly difficult. Self-diffusion of carbon occurs on length scales of $<1 \mu \mathrm{m}$ over 1 billion years in the sublithospheric mantle (Koga et al. 2003). Elemental transport of atoms bigger than carbon is expected to occur preferentially via crystal defects such as vacancies or dislocations, since the atoms are too big to fill interstitial or carbon sites in the diamond crystal lattice. Crystal defects are expected to be more common around mineral inclusions and may enhance diffusion rates of elements in the diamond crystal lattice. Chrome and Fe derived from the chromite may therefore have entered the diamond structure via imperfections in the diamond crystal lattice during residence of the diamond at high temperatures in the sublithospheric mantle or during volume expansion of the inclusion during kimberlite ascent before significant cooling to crustal temperatures occurred. We conclude that transmission electron microscopy is needed to study the detailed element distribution within the CL haloes to help determine their origin. Additionally, a micron-scale core to rim study of carbon isotopes is underway to unravel in detail the formation history of diamond \#3615 and the source of diamond forming fluids (Wiggers de Vries et al., in preparation).

\section{Conclusions}

Understanding the timing of the growth of mineral inclusions within diamonds is critical to our understanding of inclusion-based studies of the environment of diamond growth and geochronology. The technique presented here to study the genetic origin of diamond inclusions combines 3D-CL micron-scale imaging and EBSD to determine the genesis of inclusions in diamonds.

EBSD of diamond \#3615 from the Udachnaya kimberlite (Yakutia) quantitatively demonstrates identical orientations between chromite inclusions and the host, and this implies that the chromites and diamond crystallised simultaneously. The chromite inclusions record a systematic change in $\mathrm{Mg} \#$ and $\mathrm{Cr} \#$ from core to the rim of the diamond that corresponds with a $\sim 80^{\circ} \mathrm{C}$ decrease of their formation temperature, and these systematic variations also suggest a syngenetic relationship between the inclusions and the diamond. A detailed study of one of the chromites reveals it has a complex morphology with numerous small faces. The 3D geometry of diamond growth layers adjacent to the chromite is complex and layers grow around and intersect the inclusion. This geometry of the growth layers implies both protogenetic and syngenetic relationships and is interpreted to indicate a change in the relative growth rates of diamond and chromite at the diamond-chromite interface. It is suggested that in the ongoing process of crystallisation, apparent protogenetic features develop in the diamond adjacent to the chromite inclusion when diamond crystallises on chromite crystal faces. The studied chromite is therefore a syngenetic inclusion; however, annealing or recrystallisation of the chromites in the short time span between formation and entrapment by the diamond host cannot be ruled out totally from morphological observations alone.

The non-luminescent diamond CL halo with pointed features that surrounds the studied chromite inclusion is enriched in $\sim 200 \mathrm{ppm} \mathrm{Cr}$ and $\sim 80 \mathrm{ppm} \mathrm{Fe}$ and occurs across a primary diamond growth structure. The CL halo is therefore not considered a primary growth feature and is interpreted to have formed by diffusion of impurities from the chromite along crystal defects during residence of the diamond in the subcontinental lithospheric mantle or following volume expansion of the chromite inclusion during ascent of the diamond with kimberlite melts. In addition to $\mathrm{CL}$ suppression by $\mathrm{Cr}$ and $\mathrm{Fe}$ impurities, N-poor type II diamond may potentially contribute to the non-luminescent character of the CL halo. 
It is concluded that EBSD and 3D-CL micron-scale imaging can contribute to a better understanding of the complex growth histories of diamond and the inter-relations between host diamond and inclusions.

Acknowledgments K. de Corte and J. van Royen are acknowledged for their assistance with FTIR spectral analysis and W. Lustenhouwer for his constructive EMP analyses on the diamond CL halo. The authors are grateful for the helpful comments of H. Milledge and A. Van den Kerkhof. W. Griffin is thanked for PMP trace element analysis of the inclusions. O. Navon and an anonymous reviewer are gratefully acknowledged for their reviews that significantly improved the clarity of the manuscript. This study is part of the $\mathrm{PhD}$ thesis of $\mathrm{D}$. Wiggers de Vries that was financially supported by the Netherlands Organisation for Scientific Research (NWO). The FIB-SEM facility was funded by an NWO large investment subsidy. We thank the Stichting Dr. Schürmannfonds for financial support for sampling in Yakutia.

Open Access This article is distributed under the terms of the Creative Commons Attribution Noncommercial License which permits any noncommercial use, distribution, and reproduction in any medium, provided the original author(s) and source are credited.

\section{References}

Anand M, Taylor LA, Misra KC, Carlson WD, Sobolev NV (2004) Nature of diamonds in Yakutian eclogites: views from eclogite tomography and mineral inclusions in diamonds. Lithos 77:333-348

Appleyard CM, Viljoen KS, Dobbe R (2004) A study of eclogitic diamonds and their inclusions from the Finsch kimberlite pipe, South Africa. Lithos 77:317-332

Bulanova GP (1995) The formation of diamond. J Geochem Explor 53:1-23

Bulanova GP, Griffin WL, Ryan CG (1998) Nucleation environment of diamonds from Yakutian kimberlites. Mineral Mag 62:409-419

Cayzer NJ, Odake S, Harte B, Kagi H (2008) Plastic deformation of lower mantle diamonds by inclusion phase transformations. Eur J Mineral 20:333-339

De Winter DAM, Schneijdenberg CTWM, Lebbink MN, Lich B, Verkleij AJ, Drury MR, Humbel BM (2009) Tomography of insulating biological and geological materials using Focused Ion Beam (FIB) sectioning and low kV BSE imaging. J Microsc 233:372-383

Fesq HW, Bibby DM, Erasmus CS, Kable EJD, Sellschop JPF (1975) Determination of trace element impurities in natural diamonds by instrumental neutron activation analysis. In: Aherns $\mathrm{LH}$, Dawson JB, Duncan AR, Erlank AJ (eds) Physics and Chemistry of the Earth 9. Pergamon Press, New York, pp 817-836

Fliervoet TF, Drury MR, Chopra PN (1999) Crystallographic preferred orientations and misorientations in some olivine rocks deformed by diffusion or dislocation creep. Tectonophysics 303:1-27

Futergendler SI, Frank-Kamenetsky VA (1961) Oriented inclusions of olivine, garnet and chrome-spinel in diamonds. Zapisky Vsesoyuznogo Mineralogicheskogo obshestva 90:230-236 (in Russian)

Griffin WL, Ryan CG, Win TT (1993a) Trace elements in satellite minerals from the Arkangelsk kimberlites. CSIRO Restricted Report 413R, pp 106
Griffin WL, Sobolev NV, Ryan CG, Pokhilenko NP, Win TT, Yefimova ES (1993b) Trace-elements in garnets and chromites-diamond formation in the Siberian lithosphere. Lithos 29:235-256

Harris JW, Gurney JJ (1979) Inclusions in diamond. In: Field JE (ed) The properties of diamond. Academic Press, London, pp 555-591

Izraeli ES, Harris JW, Navon O (1999) Raman barometry of diamond formation. Earth Planet Sci Lett 173:351-360

Kanda H, Watanabe K (2006) Change of cathodoluminescence spectra of diamond with irradiation of low energy electron beam followed by annealing. Diam Relat Mater 15:1882-1885

Kanda H, Watanabe K, Koizumi S (2005) Change of cathodoluminescence spectra of diamond with continuous irradiation of low energy electron beam of $20 \mathrm{kV}$. Diam Relat Mater 14:561-565

Kinny PD, Griffin BJ, Heaman LM, Brakhfogel FF, Spetsius ZV (1997) SHRIMP U-Pb ages of perovskite from Yakutian kimberlites. Geologiya I Geofizika 38:91-99

Klein-BenDavid O, Izraeli ES, Hauri E, Navon O (2007) Fluid inclusions in diamonds from the Diavik mine, Canada and the evolution of diamond-forming fluids. Geochim Cosmochim Acta 71:723-744

Koga KT, Van Orman JA, Walter MJ (2003) Diffusive relaxation of carbon and nitrogen isotope heterogeneity in diamond: a new thermochronometer. Phys Earth Planet Interiors 139:35-43

Lang AR (1967) Causes of birefringence in diamond. Nature 21:248-251

Leeder O, Thomas R, Klemm W (1987) Einschlusse in Mineralien. VEB Deutscher Verlag fur Grunstoffenindustrie, Leipzig, $180 \mathrm{pp}$

Mendelssohn MJ, Milledge HJ (1995) Geologically significant information from routine analysis of the mid-infrared spectra of diamonds. Int Geol Rev 37:95-110

Meyer HOA (1985) Genesis of diamond: a mantle saga. Am Mineral 70:344-355

Meyer HOA (1987) Inclusions in diamond. In: Nixon PH (ed) Mantle Xenoliths. Wiley, London, pp 501-523

Milledge HJ, Mendelssohn MJ, Boyd SR, Pillinger CT, van Heerden LA, Seal M (1989) IR, CL and MS data for Finsch diamonds and an Argyle stone exhibiting giant platelets. Diamond Conference Abstracts, Bristol (unpublished)

Mitchell RS, Giardini AA (1953) Oriented olivine inclusions in diamond. Am Mineral 38:136-138

Nasdala L, Hofmeister W, Harris JW, Glinnemann J (2005) Growth zoning and strain patterns inside diamond crystals as revealed by Raman maps. Am Mineral 90:745-748

Navon O, Hutcheon ID, Rossman GR, Wasserburg GJ (1988) Mantlederived fluids in diamond micro-inclusions. Nature 335:784-789

Orlov JL (1977) The mineralogy of diamond. Wiley, New York, $235 \mathrm{pp}$

Pagel M, Barbin V, Blanc P, Ohnenstetter D (2000) Springer, Berlin, $514 \mathrm{pp}$

Palmer DW (1994) In: Davies G (ed) Properties and growth of diamond. INSPEC, Institute of Electrical Engineers, London, pp 143-152 (EMIS, Datareviews Series)

Pearson DG, Shirey SB (1999) Isotopic dating of diamonds. In: Lambert D, Ruiz J (eds) Economic Geological Special Publications, SEG reviews, vol 12, pp 143-171

Pearson DG, Kelley SP, Pokhilenko NP, Boyd FR (1997) Laser ${ }^{40} \mathrm{Ar} /{ }^{39} \mathrm{Ar}$ dating of phlogopites from southern African and Siberian kimberlites and their xenoliths: Constraints on eruption ages, melt degassing and mantle volatile compositions. Russ Geol Geophys 38:106-117

Pearson DG, Shirey SB, Bulanova GP, Carlson RW, Milledge HJ (1999) Re-Os isotope measurements of single sulfide inclusions in a Siberian diamond and its nitrogen aggregation systematics. Geochim Cosmochim Acta 63:703-711 
Pidgeon RT (1992) Recrystallisation of oscillatory zoned zircon: some geochronological and petrological implications. Contrib Mineral Petrol 110:463-472

Prior DJ, Boyle AP, Brenker F, Cheadle MC, Day A, Lopez G, Peruzzo L, Potts GJ, Reddy S, Spiess R, Timms NE, Trimby P, Wheeler J, Zetterstrom L (1999) The application of electron backscatter diffraction and orientation contrast imaging in the SEM to textural problems in rocks. Am Mineral 84:1741-1759

Promprated P, Taylor LA, Anand M, Floss C, Sobolev NV, Pokhilenko NP (2004) Multiple-mineral inclusions in diamonds from the Snap Lake/King Lake kimberlite dike, Slave craton, Canada: a trace-element perspective. Lithos 77:69-81

Raal FA (1957) A spectrographic study of the minor element content of diamond. Am Mineral 42:354-361

Reed SJB (2005) Electron microprobe analysis and scanning electron microscopy in geology, 2nd edn. Cambridge University Press, Cambridge, $189 \mathrm{pp}$

Richardson SH, Harris JW (1997) Antiquity of peridotitic diamonds from the Siberian craton. Earth Planet Sci Lett 151:271-277

Schrauder M, Navon O (1994) Hydrous and carbonatitic mantle fluids in fibrous diamonds from Jwaneng, Botswana. Geochim Cosmochim Acta 58:761-771

Sobolev NV (1977) Deep-seated inclusions in kimberlites and the problem of the composition of the upper mantle. American Geophysical Union, Washington, DC, 279 pp

Sobolev NV, Galimov EM, Ivanovskaya IN, Yefimova ES (1979) Isotope composition of carbon in diamonds containing crystalline inclusions. Doklady Akademii Nauk SSSR 249:1217-1220

Sobolev NV, Logvinova AM, Efimova ES (2009) Syngenetic phlogopite inclusions in kimberlite-hosted diamonds: implications for role of volatiles in diamond formation. Russ Geol Geophys 50:1234-1248
Spetsius ZV, Belousova EA, Griffin WL, O'Reilly SY, Pearson NJ (2002) Archean sulfide inclusions in Paleozoic zircon megacrysts from the Mir kimberlite, Yakutia: implications for the dating of diamonds. Earth Planet Sci Lett 199:111-126

Taylor LA, Anand M (2004) Diamonds: time capsules from the Siberian mantle. Chemie Der Erde 64:1-74

Taylor WR, Jaques AL, Ridd M (1990) Nitrogen-defect aggregation characteristics of some Australasian diamonds-time-temperature constraints on the source regions of pipe and alluvial diamonds. Am Mineral 75:1290-1310

Taylor LA, Anand M, Promprated P (2003a) Diamond and their inclusions: are the criteria for syngenesis valid? 8th International Kimberlite Conference. Long Abstract, Victoria, Canada

Taylor LA, Anand M, Promprated P, Floss C, Sobolev NV (2003b) The significance of mineral inclusions in large diamonds from Yakutia, Russia. Am Mineral 88:912-920

Van den Kerkhof AM, Hein UF (2001) Fluid inclusion petrography. Lithos 55:27-47

Van den Kerkhof AM, Kronz A, Simon K, Scherer T (2004) Fluidcontrolled quartz recovery in granulite as revealed by cathodoluminescence and trace element analysis (Bamble sector, Norway). Contrib Mineral Petrol 146:637-652

Vance JA (1965) Zoning in igneous plagioclase: patchy zoning. J Geol 73:636-651

Wang W (1998) Formation of diamond with mineral inclusions of "mixed" eclogite and peridotite paragenesis. Earth Planet Sci Lett 160:831-843

Wirth R (2009) Focused Ion Beam (FIB) combined with SEM and TEM: advanced analytical tools for studies of chemical composition, microstructure and crystal structure in geomaterials on a nanometre scale. Chem Geol 261:217-229 